\title{
FDA-Regulated Drug Study Indicator
}

National Cancer Institute

\section{Source}

National Cancer Institute. FDA-Regulated Drug Study Indicator. NCI Thesaurus. Code C123630.

An indication as to whether the study involves an FDA-regulated drug. 